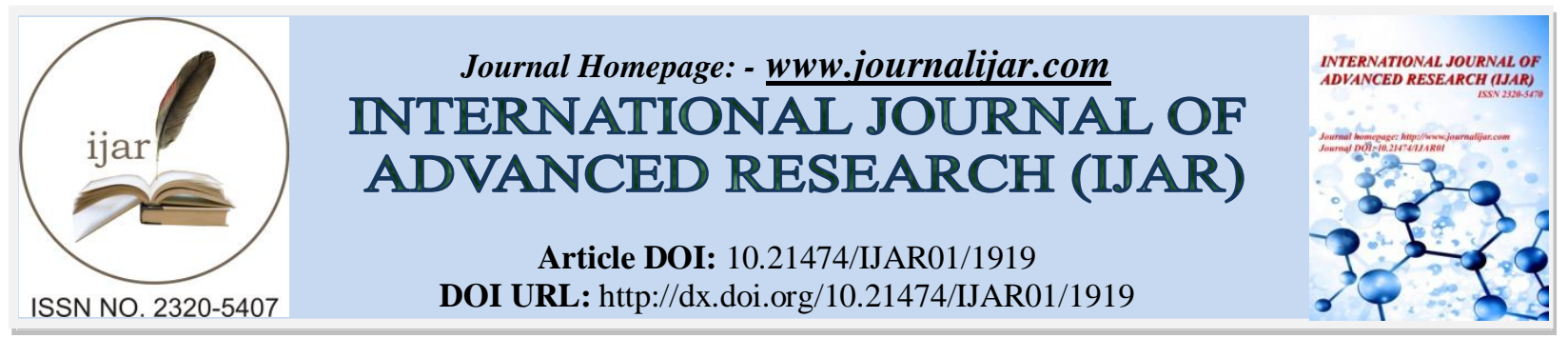

RESEARCH ARTICLE

\title{
CURCUMIN INDUCED APOPTOSIS VIA G2/M ARREST IN HUMAN OVARIAN CANCER CELLS.
}

\author{
Jihye Kim.
}

Korean Medicine Application Center, Korea Institute of Oriental Medicine, Daegu 41060, Korea.

\section{Manuscript Info}

Manuscript History

Received: 12 August 2016

Final Accepted: 22 September 2016

Published: October 2016

Key words:-

curcumin, ovarian cancer cells, G2/M arrest

\begin{abstract}
The goal of this study carried out to investigate suppression ability by curcumin against proliferation of ovarian cancer cells. When curcumin was treated for 0,24 , and $48 \mathrm{~h}$ from 0 to $90 \mu \mathrm{M}$ concentrations, PA-1 cells were discovered by decreased survival ratio depending on the concentration and time. The $\mathrm{IC}_{50}$ concentrations from 24 and $48 \mathrm{~h}$ treated cells were found to 19.7 and $4.4 \mu \mathrm{M}$, respectively. To investigate the function of curcumin on cell cycle, PA-1 cells treated with $5 \mu \mathrm{M}$ curcumin were observed with FACS at 24 and $48 \mathrm{~h}$. As a result, a number of cells in G1 stage of cycle increased depending on the elapsed times, and caused G2/M arrest. Therefore, it is assumed that curcumin plays an effective role in ovarian cancer cells as an antiproliferative agent via $\mathrm{G} 2 / \mathrm{M}$ arrest.
\end{abstract}

Copy Right, IJAR, 2016,. All rights reserved.

\section{Introduction:-}

Ovarian cancer is the fifth cause disease of cancer death in women worldwide. Since this cancer is the lack of early symptoms, $70 \%$ of the diagnosis from this disease is found in a progressed state. Ovarian cancer mutated in BRCA1/2 gene is particularly sensitive to the substances that cause DNA double strand breaks (DSBs) and DNA interstrand cross-links (Mangerich, 2011; Underhill, et al., 2011).

Curcumin (diferuloymethane) is extracted from the rhizome of an indian traditional medicine turmeric (Curcuma longa Linn) (Chainani-Wu, 2003), which has antiangiogenic, antiproliferative, antitumorigenic, antioxidant, and anti-inflammatory properties (Anand, et al., 2008). Curcumin is associated with negative regulation of oncogenic proteins including growth factors, protein kinases, transcription factors, inflammatory cytokines, and cell receptors (Anand, et al., 2008). In addition, curcumin has antiproliferative effects on cancer cell via induction of apoptosis through regulation of cell cycle factors (Anand, et al., 2008; Deguchi, 2015).

Curcumin is synthesized from 4-hydroxycinnamic acid of shikimate pathway (Carocho and Ferreira, 2013). The substance is primarily metabolized in liver to glucuronides such as curcumin (THC), hexahydrocurcumin (HHC), dihydrocurcumin, and sulfate conjugates as main metabolite (Holder, et al., 1978; Ravindranath and Chandrasekhara, 1980; Pan, et al., 1999; Varred, et al., 2008).

Curcumin has been studied in multiple human carcinomas including melanoma, head and neck, breast, colon, pancreatic, prostate and ovarian cancers (Wilken et al., 2011). Earlier studies have shown the effect of curcumin as an antioxidant, antibacterial, and antitumor. In addition, it also has a noteworthy role in the control of differentdiseases(Rahmani et al., 2014). 
The goal of this study carried out to investigate suppression ability by curcumin against proliferation of ovarian cancer cells.

\section{Materials and Methods:-}

Sample preparation and assay were carried out according to the modified method as described by Seo et al. (2016).

\section{Results and Discussion:-}

In this study, when PA-1 cells was treated for 0,24 , and $48 \mathrm{~h}$ by $0,3,10,30$, and $90 \mu \mathrm{M}$ curcumin concentrations, the cells were discovered by the decreased survival ratio depending on concentration and time (Fig. 1).

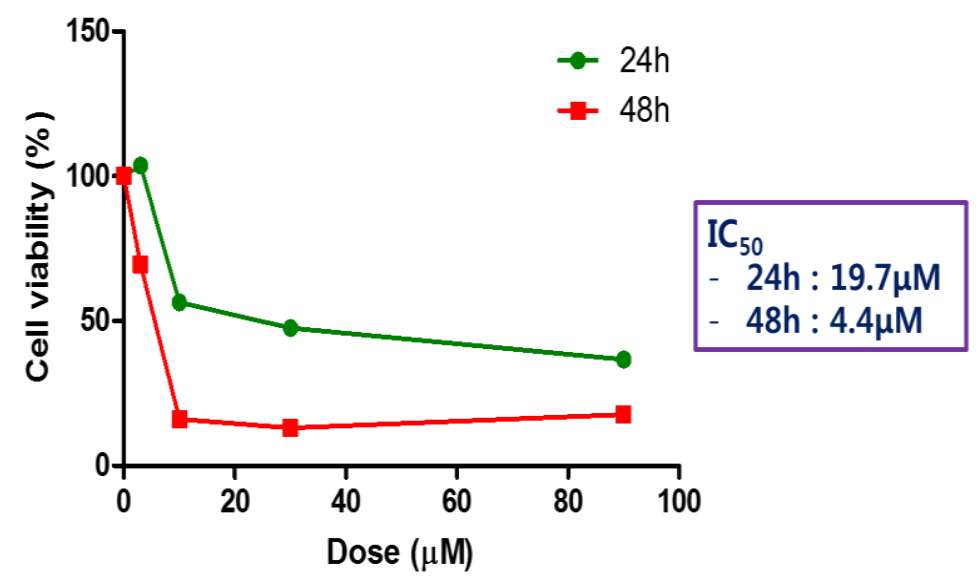

Fig. 1. Analysis of cell viability according to curcumin concentration and time. Curcumin of each concentration was treated for the indicated concentration and time. $\mathrm{X}$ - and $\mathrm{Y}$-axes mark the treated curcumin concentration and cell viability, respectively.

Different concentrations of curcumin inhibited the proliferation of PA-1 cells. The treated cells with curcumin showed greater apoptosis than that of the untreated cells. $\mathrm{IC}_{50}$ concentrations under the treated conditions at 24 and $48 \mathrm{~h}$ were presented by 19.7 and $4.4 \mu \mathrm{M}$, respectively. Curcumin inhibits metalloproteinase-2 (MMP-2) in a concentration and time-dependent manner, and suppresses H-Ras-induced invasive phenotype of MCF10A human breast epithelial cells (H-ras MCF10A) (Kim et al., 2001).Therefore, it is assumed that the mechanism for action of curcumin is similar to PA-1 and H-ras MCF10A cells derived from ovarian and breast cancers, respectively. Cells induced into apoptosis have DNA content less than 2n owing to DNA fragmentation by endonuclease during apoptosis. Furthermore, G1 stage in cell cycle increases owing to the occurrence of abnormal cells, and change in the number of cells plays a role as an indicator for analysis of apoptosis cells (Nicoletti, et al., 1991; Riccardi and Nicoletti, 2006).

In order to examine the changes in cell cycle due to curcumin in this study, PA-1 cells were treated for 0,24 , and 48 $\mathrm{h}$ at $5 \mu \mathrm{M}$ curcumin and observed by FACS (Fig. 2A). As shown in Fig. 2B, when compared with 0 h, number of cells in sub G1 stage was increased by approximately 2 and 4 folds at 24 and 48 h, respectively. Kim et al. (2013) reported that curcumin inhibited proliferation of cervical cancer cells in a dose- and time-dependent manner, and induced apoptotic cell death (increase of AnnexinV-positive and SubG1 fraction).

Number of cells in G0/G1 phase was decreased in cells treated for 24 and $48 \mathrm{~h}$ with curcumin, whereas those of S and $\mathrm{G} 2 / \mathrm{M}$ phases were increased for the same treated times (Fig. 2B). When $24 \mathrm{~h}$-treated cells with curcumin were compared with 0 h-treated cells, numbers of cells in G0 and S phases were decreased, but one in G2/M phase was increased. In $48 \mathrm{~h}$-treated cells, cells in G0/G1 phase was decreased below 4 fold when compared with $0 \mathrm{~h}$, but those in $\mathrm{S}$ and G2/M phases were increased. Therefore, when compared with $0 \mathrm{~h}$, it is estimated that the 24 - and $48 \mathrm{~h}$ treated cells decreased numbers of G0/G1 cells, but increased the numbers in S and G2/M phases as much as decrease of numbers of G0/G1 cells. Since number of a few cells was increased in S phase at $48 \mathrm{~h}$-treated cells, the treated condition was induced into partial arrest in cell cycle. 
A
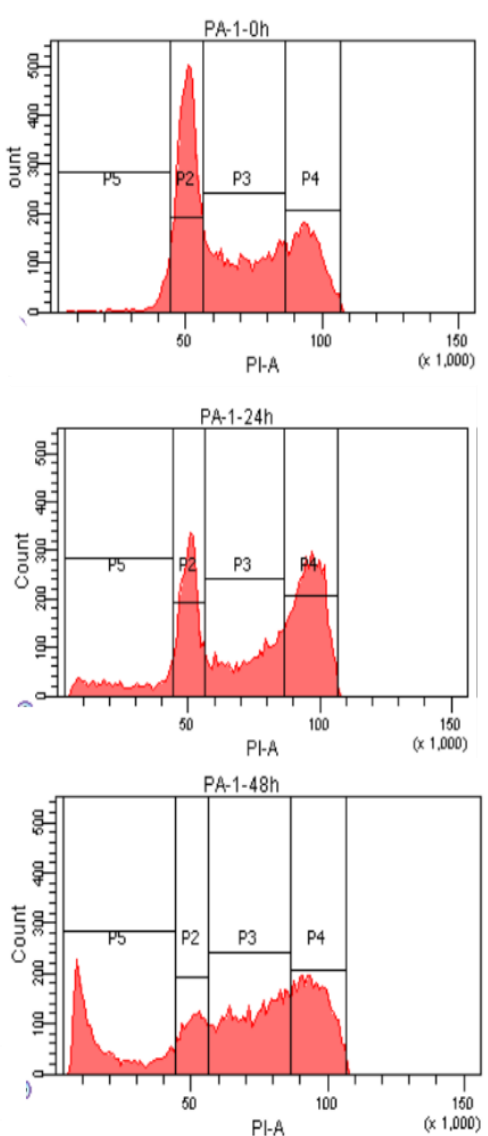

B
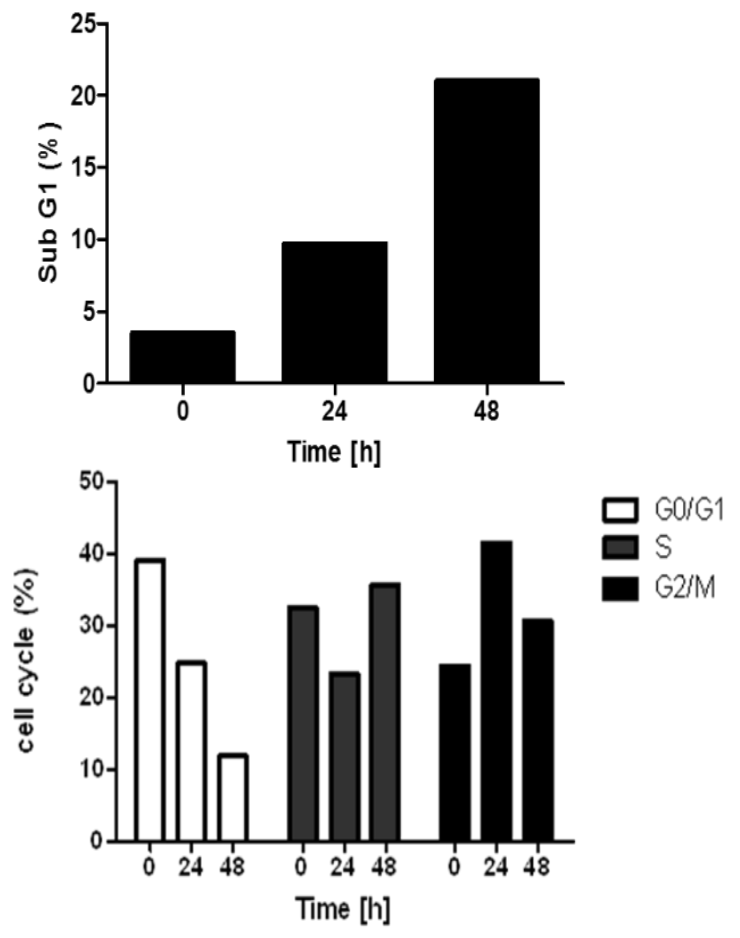

Fig. 2. Evaluation of effect on cell cycle by curcumin treatment. (A) Results of FACS and (B) analysis of population for each phase in cell cycle. Curcumin was treated for 0,24 , and $48 \mathrm{~h}$ at $5 \mu \mathrm{M}$ curcumin. (A) Upper panel, 0 h-treated PA-1 cells; middle panel, 24 h-treated PA-1 cells; lower panel, 48 h-treated PA-1 cells. (B) Upper panel, sub G1 population; lower panel, analysis of population for each phase in cell cycle.

However, G2/M arrest was observed by highly increased ratios of cell populations in 24 and $48 \mathrm{~h}$-treatments with curcumin. Curcumin triggers G2/M arrest in U87 human glioma cells, and induces apoptosis via FoxO1 signaling (Gheng, et al., 2016). Otherwise, curcumin causes G1/S or G2/M arrest via interaction with various factors related with cell signaling (Luthra and LaI, 2016; Seo et al., 2016). Therefore, it is assumed that PA-1 cell originated from ovarian cancer causes apoptosis via G2/M arrest.

In summary, when treated with curcumin against PA-1 of ovarian cancer cell, cell death occurs depending on concentration and time, and showed a trend that is accumulated in G2/M phases of cell cycle. Therefore, we suggest that curcumin shows effects of anticancer by antiproliferation via apoptosis.

\section{References:-}

1. Anand, P., Thomas, S. G., Kunnumakkara A. B., Sundaram, C., Harikumar, K. B., Sung, B., Tharakan, S. T., Misra, K., Priyadarsini, I. K., Rajasekharan, K. N. and Aggarwal, B. B. 2008. "Biological activities of curcumin and its analogues (Congeners) made by man and Mother Nature," Biochemical Pharmacology, 76 (11): 15901611 ,

2. Chainani-Wu, N. 2003. "Safety and anti-inflammatory activity of curcumin: a component of tumeric (Curcuma longa)," Journal of Alternative and Complementary Medicine, 9 (1): 161-168.

3. Carocho, M. and Ferreira, I. C. F. R. 2013. "The role of phenolic compounds in the fight against cancer-a review," Anti-Cancer Agents in Medicinal Chemistry, 13 (8): 1236-1258.

4. Deguchi, A. 2015. "Curcumin targets in inflammation and cancer," Endocrine, Metabolic \& Immune Disorders-Drug Targets, 15 (2): 88-96. 
5. Holder, G. M., Plummer, J. L. and Ryan, A. J. 1978. "The metabolism and excretion of curcumin (1,7-bis-(4hydroxy-3-methoxyphenyl)-1,6-heptadiene-3,5-dione) in the rat," Xenobiotica, 8 (12): 761-768.

6. Kim, B., Jung, E. J. and Song, Y. S. 2013. Abstract 4036: Curcumin induces ER stress-mediated apoptosis through cell type-specific interruption of redox balance in cervical cancer cells. Cancer Res. Proceedings: AACR 104 $4^{\text {th }}$ Annual Meeting, Washington, DC.

7. Kim, M. S., Kang, H. J. and Moon, A. 2001.Inhibition of invasion and induction of apoptosis by curcumin in Hras-transformed MCF10A human breast epithelial cells. Arch Pharm Res. 24: 349-354.

8. Luthra, P. M. and Lal, N. 2016.Prospective of curcumin, a pleiotropic signaling molecule from Curcuma longa in the treatment of Glioblastoma. Eur J Med Chem. 109: 23-35.

9. Mangerich, A. and Bürkle, A. 2011. How to kill tumor cells with inhibitors of poly (ADP-ribosyl)ation. Int. J. Cancer 128: 251-265.

10. Nicoletti, I., Migliorati, G., Pagliacci, M. C., Grignani, F. and Riccardi, C. 1991. "A rapid and simple method for measuring thymocyte apoptosis by propidium iodide staining and flow cytometry". Journal of Immunological Methods 139 (2): 271-279.

11. Pan, M.-H., Huang, T.-M. and Lin, J.-K. 1999. "Biotransformation of curcumin through reduction and glucuronidation in mice," Drug Metabolism \& Disposition, 27 (4): 486-494.

12. Ravindranath, V. and Chandrasekhara, N. 1980. "Absorption and tissue distribution of curcumin in rats," Toxicology, 16 (3): 259-265.

13. Riccardi, C. and Nicoletti, I. 2006. "Analysis of apoptosis by propidium iodide staining and flow cytometry". Nature Protocols 1 (3): 1458-1461.

14. Seo, J. A., Kim, B., Dhanasekaran, D. N., Tsang, B. K. and Song, Y. S. 2016. Curcumin induces apoptosis by inhibiting sarco/endoplasmic reticulum Ca2+ ATPase activity in ovarian cancer cells. Cancer Lett. 37 (1): 30 37.

15. Underhill, C., Toulmonde, M. and Bonnefoi, H. 2011. A review of PARP inhibitors: From bench to bedside. Ann. Oncol. 22: 268-279.

16. Vareed, S. K., Kakarala, M., Ruffin, M. T., Crowell, J. A., Normolle, D. P., Djuric, Z., Brenner, D. E. 2008. "Pharmacokinetics of curcumin conjugate metabolites in healthy human subjects," Cancer Epidemiology Biomarkers \& Prevention, 17 (6): 1411-1417. 